\title{
Brouillons et versions inédites de poèmes d'Henry Bauchau
}

Le sang vertical ${ }^{1}$

Du sang d'un bel entier

où la langue d'argile

une parole sur le monde

une parole sur la joie

dite par le pollen de juin

par la rose la plus sauvage

et par l'ombre sur ton visage

et par une l'ombre sur ton visage

un

łe pays des bêtes gracieuses

où se blottit la giboulée

Du sang du corps entier

d'une langue d'amour

une parole primevère

une parole de vertige

une parole de vertige

une pare

une méditation de l'air

une

Du sang du corps entier

d'une langue d'amour

une parole primevère

${ }^{1}$ FHB-A430. Les codes de transcription sont les suivants : les mots barrés sont raturés dans les manuscrits, les mots en gras sont ajoutés dans l'interligne et remplacent d'autres mots et les mots en italique sont ajoutés en tête de vers sans suppression d'éléments dans le vers. 
une méditation de l'air une écriture de vertige une parole de prodige et d'un vocable vertical L'architecture de la joie 


\section{Les Genêts}

L'enfant trouve dans l'incendie la terre aux genêts éclatants.

Pourquoi t'en détourner ma vie et te chercher en pourrissant?

À ce qui respire en prière il n'y a que la vie de l'âme. Il n'y a que la vie en flamme au retour à l'enfant sévère.

Désir engendre pestilence, à moins que l'âme ait retrouvé

L'unique porte dérobée vers ce qui souffre violence. Que l'esprit frappe aux nombres d'or, lorsque celui qui vient sans bruit

L'aura trouvé veillat la nuit, il pourra traverser la mort.

Mille rameaux sont dans les airs, il a fallu se perdre au monde.

Gardant le ciel et la racine, il a fallu prendre l'émonde Pour que la sève s'illumine aux rayons de la terre entière.

Du poème aux milliers de têtes vers le psaume à l'unique chant

Des forêts aux profondes mers, il n'y a qu'un seul mouvement

Qui chante impersonnellement aux marées de la terre entière.

${ }^{2}$ FHB-A14908. 


\title{
Chemin du monde ${ }^{3}$
}

\author{
L'enfant trouve dans l'incendie \\ La terre aux genêts éclatants \\ Pourquoi t'en détourner ma vie \\ Et te chercher en pourrissant?
}

Tout ce qui vit, vit en prière, Et le monde était vie de l'âme. Et la vie était vie en flammes, Quand la vivant l'enfant sévère

Dans la sève où nait le poème, Dans le cœur où combat le sang, Des forêts aux profondes mers

Une voix monte vers le ciel, Une voix chante impersonnelle Aux marées de la terre entière

\section{L’homme bariolé de songes ${ }^{4}$}

Terre d'ombre ou terre brûlée Femme à l'invincible distance

Astres morts ou l'astre tombé sous la griffe de ta naissance

Dieux de limaille faisant semailles dans tes paumes Tu parcours l'inquiète planète Homme bariolé de songes et d'héritages et d'écritures de squelettes

\footnotetext{
${ }^{3}$ FHB-A2150.
}

${ }^{4}$ FHB-A2363. 
En minutieux solfèges de pavés comme en cortèges de dentelles

Composant l'heure verticale

Où, selon l'instrument des couleurs, déchiffrer

Ceints de sybilles ambiguës

Le tramway rouge Éphèse ou, plus noir, le train bleu. 


\section{Port Royal $1^{5}$}

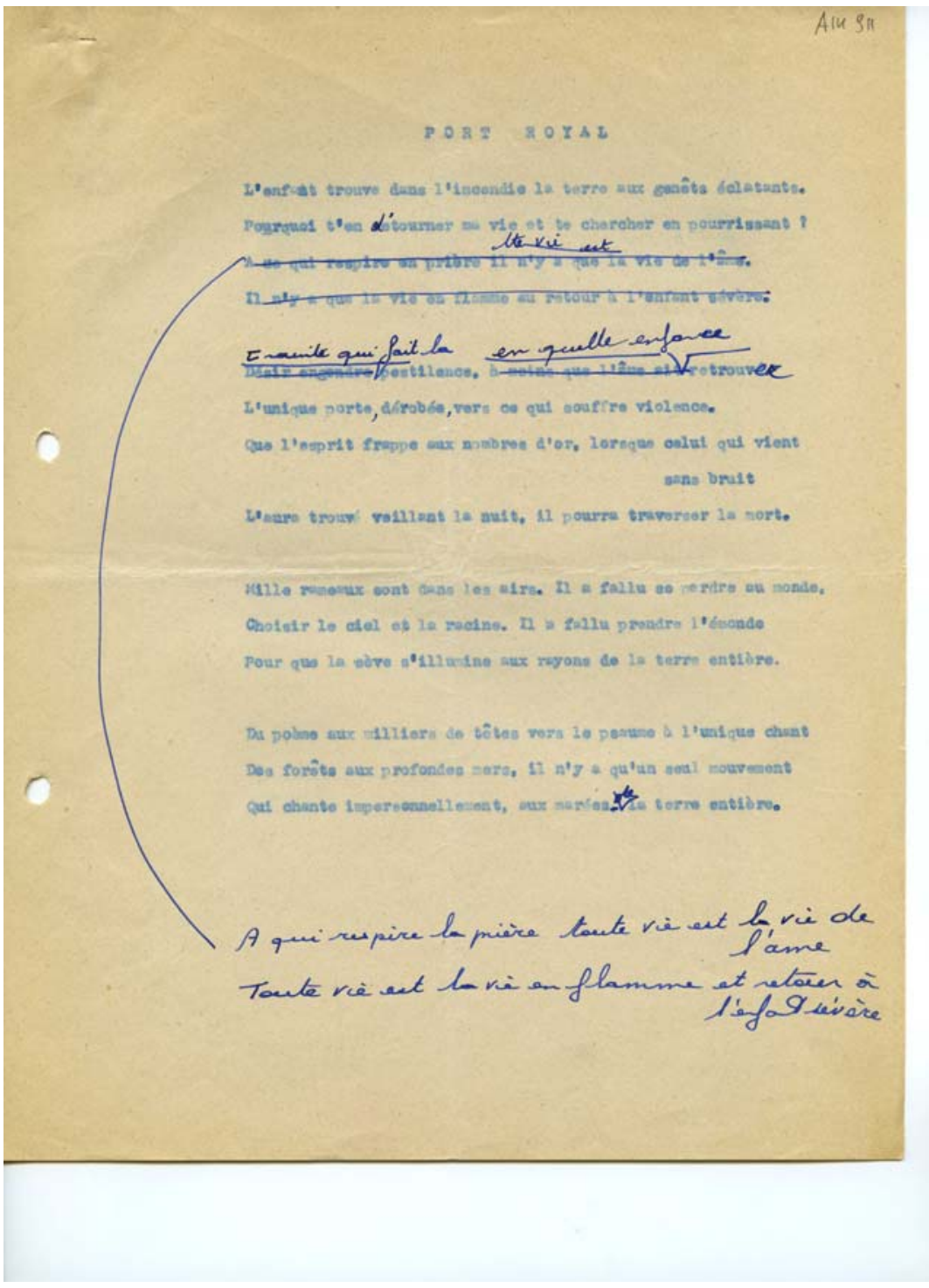

${ }^{5}$ FHB-A14911. 


\section{Les sandales éclatantes ${ }^{6}$}

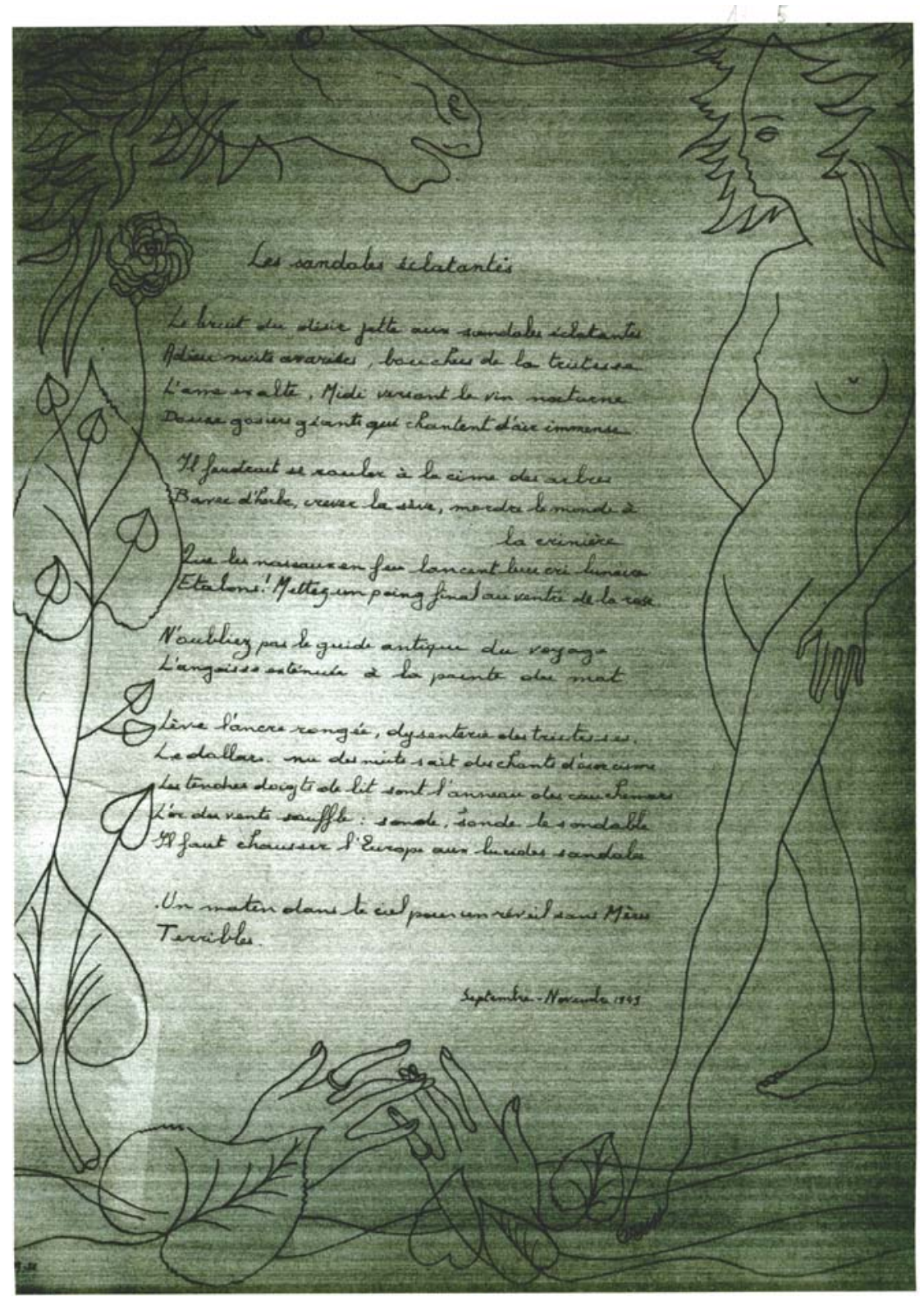

${ }^{6}$ FHB-A2025. 